\title{
Optimization of Extraction of Anthocyanins from Roselle (Hibiscus sabdariffa var. sabdariffa) in Aqueous Medium
}

\author{
GHANENDRA GARTAULA* and DHAN BAHADUR KARKI
}

\author{
Central Department of Food Technology, Tribhuvan University, Dharan, Nepal
}

The dried roselle (Hibiscus sabdariffa var. sabdariffa) calyces were studied for the extraction of anthocyanin in aqueous solution. The total anthocyanin content in dried roselle powder was found to be $310.48 \mathrm{mg} / 100 \mathrm{~g}$ of dry matter. The extraction temperature at $70^{\circ} \mathrm{C}$ gave the highest yield (66.69-70.61\%), while at $90^{\circ} \mathrm{C}$ the degradation of anthocyanins occurred. The solid-liquid ratio revealed no significant effect $(p>0.05)$, whereas the particle size showed a significant effect $(p<0.05)$ on the extraction of anthocyanin. The yields of anthocyanin extraction for 300 and $600 \mu \mathrm{m}$ particle powders were significantly higher $(p<0.5)$ than that of $1180 \mu m$ powder. Reduction in the particle size inversely increased the yield of anthocyanins. In conclusion, the extraction of anthocyanin from dried roselle calyces with an average particle size of $600 \mu \mathrm{m}$ using a solid-liquid ratio of 1:50 in aqueous medium with $\mathrm{pH} 7.0$ at $70^{\circ} \mathrm{C}$ for $20 \mathrm{~min}$ showed the maximum yield (69.84\%).

Keywords: Anthocyanin, Roselle, Calyx, Extraction condition, Solid-liquid ratio

\section{Introduction}

Color is an important factor in influencing consumers' acceptability of any food products. It is highly appreciated for its aesthetic role as well as a basis for the quality. In this latter respect, color gives visual cues to flavor identification and taste thresholds, influencing food preferences, food acceptability and ultimately food choice. Most food nowadays is processed in some way before reaching the consumer and manufacturers have a need to replace colour lost during processing or to colour products which would otherwise be colorless and unappealing. With increasing public concern on the safety of synthetic colorants, natural pigments are assuming greater prominence (Bridle and Timberlake, 1997). The pigments and colour precursors found in fruits and vegetables occur for the most part in cellular plastid inclusions (e.g. chloroplasts and other chromoplasts) and to a lesser extent dissolved in fat droplets or water within the cell protoplast and vacuole. These pigments can be classified into four major groups; chlorophylls, carotenoids, anthocyanins and anthoxanthins. Pigments belonging to the latter two groups are also referred to as flavonoids (Potter and Hotchkiss, 1996). Anthocyanins are the water-soluble pigments responsible for the brilliant orange red through deep purple colors in flowers and fruits (Wong, 1996). In food plants, anthocyanins are widespread occurring in at least 27 families, 73 genera and a multitude of species. It is reasonable to assume; therefore, that human beings are well conditioned to ingesting anthocyanins; further, it may be argued that the present day diet with its increasing dependence on processed foods has become deficient in anthocyanins (Bridle and Timberlake, 1997). At present, the role of anthocyanins as food colorant is becoming increasingly important. Not only do they contribute to the most important attributes of foodboth for aesthetic value and for quality judgment, but also they tend to yield potential health effects, as they have been

\footnotetext{
*Correspondent author, E-mail: ghanendra@gmail.com
}

observed to possess potent antioxidant properties (Tsai et al., 2002). The biological effect of anthocyanins in human low density lipoprotein and lecithin-liposome systems have been reported (Meyer et al., 1997; Satue-Gracia et al., 1997). The anthocyanins are not only non-toxic and non-mutagenic but also have positive therapeutic properties for instance, in ophthalmology for the treatment of various circulatory disorders and inflammatory diseases (Bridle and Timberlake, 1997).

\section{Materials and Methods}

Raw materials: Fresh mature roselle (Hibiscus sabdariffa var. sabdariffa) calyces were brought from Gaurigunj-8 of Jhapa District, Nepal. The calyces were separated manually, cleaned in clean water and drained. The calyces were then dried intermittently in the cabinet drier $\left(\mathrm{REICO}^{\circledR}\right)$ at $55 \pm 5^{\circ} \mathrm{C}$. The dried calyces were packed in double Polythene (PE) pouches, kept in black PE bag and stored at $-28^{\circ} \mathrm{C}$ (deep fridge) until use. Prior to analysis, the calyces were milled in a mixer blender $\left(\mathrm{PICASSO}^{\circledR)}\right.$. The powdered calyces were then sieved through three different standard sizes of 300, 600 and $1180 \mu \mathrm{m}$ (Sethi Standard Test Sieves).

Methodology: Moisture content (Hot air oven method), crude fat (Ether extraction method), protein (Micro-Kjeldahl), crude fiber, ash content and total acidity were determined as per Ranganna, (2007). The aqueous extraction of the powdered calyces was carried out at three different $\mathrm{pH}$, viz. $\mathrm{pH}$ 4, 7 and 9 at different times and temperatures. The $\mathrm{pH}$ was maintained using citric acid monohydrate (Qualigenes Fine Chemicals, India), sodium bicarbonate (Merck Limited, India) and sodium hydroxide (Qualigenes Fine Chemicals, India) respectively. A portable $\mathrm{pH}$ tester (HANNA ${ }^{\circledR}$, Hanna Instruments HI96107) was used to monitor the $\mathrm{pH}$. The extraction of the roselle powder was carried out in water bath (SHAKER BATH SBS $30^{\circledR}$, UK (for $90 \pm 2^{\circ} \mathrm{C}$ ) and Clifton ${ }^{\circledR}$ Nickel Electro Limited, England (for $70 \pm 2^{\circ} \mathrm{C}$ and $50 \pm 2^{\circ} \mathrm{C}$ ). The incubation temperature 
and heating time used were $90 \pm 2^{\circ} \mathrm{C}(10,20$ and $30 \mathrm{~min}), 70 \pm 2^{\circ} \mathrm{C}$ (20, 40 and $60 \mathrm{~min}), 50 \pm 2^{\circ} \mathrm{C}(20,40$ and $60 \mathrm{~min})$ and $32 \pm 2^{\circ} \mathrm{C}(30$, 60 and $90 \mathrm{~min}$ ). Once the thermal treatment was completed the conical flasks were taken out and brought to room temperature $\left(32 \pm 2^{\circ} \mathrm{C}\right)$ immediately then filtered. A particle size of $1180 \mu \mathrm{m}$ and solid-liquid ratio of 1:100 was used in the first set of experiment. In the second set of experiment, the extraction was carried out for $20 \mathrm{~min}$ using solvent of $\mathrm{pH} 7$, at $70 \pm 2^{\circ} \mathrm{C}$. The particle sizes were varied, viz., 300, 600 and $1180 \mu \mathrm{m}$. Similarly, the solid-liquid ratio was also varied, as 1:50, 1:100 and 1:150. The aqueous extraction was carried out as per the method described by Tsai et al., (2002). For the extraction of total anthocyanins roselle powder was soaked in distilled water and ground in a mortar and pestle. The process was continued until the residue was colourless. The volume was made up $50 \mathrm{ml}$ in a conical flask. The extract was then filtered for further analyses purposes.

The $\mathrm{pH}$ of the extract was measured using portable $\mathrm{pH}$ tester $\left(\right.$ HANNA $\left.^{\circledR}\right)$. The total acidity of the extract was measured as per Ranganna, (2007). From the total acidity, the percentage (\%) extraction of acid was calculated. The total anthocyanin of the extract was measured as per Srivastava and Kumar, (2002) with some modification. Three $\mathrm{ml}$ of the extract was taken and diluted to $15 \mathrm{ml}$ with $0.1 \mathrm{~N} \mathrm{HCl}$. It was then allowed to equilibrate in dark for $1 \mathrm{hr}$. The absorbance was measured at $32 \pm 2{ }^{\circ} \mathrm{C}$ and $510 \mathrm{~nm}$ using a spectrophotometer (Digital Spectrophotometer, Model 305).

Calculation: Total OD $/ 50 \mathrm{ml}=\left(\mathrm{OD}^{*}\right.$ volume made up $* 50 / \mathrm{ml}$ juice taken),

Total anthocyanins $(\mathrm{mg} / 50 \mathrm{ml})=($ Total OD $/ 50 \mathrm{ml}) / 87.3$

The total anthocyanin was expressed on percentage dry basis.

Statistical analysis: The analysis were carried out in triplicates and all the data were calculated using Microsoft Office Excel (2003), and reported as means \pm SD (standard deviation). The statistics significance was evaluated by Analysis of Variance (ANOVA) (two-way, no blocking, all interactions) using Genstat Discovery Edition 3.0. The means of the data were compared using Least Significant Difference (LSD) method at $5 \%$ level of significance $(\mathrm{p}<0.05)$.

\section{Results and Discussion}

Proximate composition: The crude protein, ether extract, crude fiber, ash and acidity content (dry basis) of roselle was found to be $13.57 \pm 0.85 \%, 2.38 \pm 0.22 \%, 8.80 \pm 0.45 \%, 6.23 \pm 0.31 \%$ and $33.05 \pm 1.58 \%$ respectively. The ethereal extract and the crude fiber was found quite lower than that given in The Wealth of India (1997). However, the results were at par with that given by Babalola et al. (2001).

Total anthocyanins: The total anthocyanins of the roselle was found to be $310.48 \mathrm{mg} / 100 \mathrm{~g}$ (dry basis). This constitutes only about $20.7 \%$ of that reported by Du and Francis (1973).
This might be due to the longer storage time which caused the degradation of anthocyanins to such an extent (Marti et al., 2001; Alighourchi and Barzegar, 2009). Though degradation might have occurred, this is considered a good yield compared with some natural pigments reported in the literatures, such as in grapes (Dieci, 1967), red cabbage (Idaka, 1987-88), elderberry (Bronnum-Hansen et al., 1985), blackberry (Fan-Chiang and Wrolstad, 2005), strawberry (da Silva et al., 2007), wood sorrel (Pazmino-Duran et al., 2001) and black sorghum bran (Awika et al., 2004), to name a few.

Extraction of the powder: In the preliminary experiment, $\mathrm{pH}$ of the solvent, extraction time and extraction temperature were varied. Extraction was carried out at solvent $\mathrm{pHs}$ of 9, 7 and 4, extraction temperatures of $32 \pm 2,50 \pm 2,70 \pm 2$ and $90 \pm 2^{\circ} \mathrm{C}$, and extraction times varying from 10 to $90 \mathrm{~min}$. The particle size was $1180 \mu \mathrm{m}$ and solid-liquid ratio (S/L) was 1:100.

Effect of particle size and solid-liquid ratio on $\mathrm{pH}$, acidity and anthocyanins of the extract: From the preliminary experiment, it was found that the temperature is the only factor that affected the extraction of anthocyanins from the roselle powder. The $\mathrm{pH}$ of the solvent and the extraction time had no significant effect $(p>0.05)$ on the extraction of anthocyanins. Extraction temperature of $70^{\circ} \mathrm{C}$ gave the highest yield. Hence, the second study was conducted using the solvent of $\mathrm{pH} 7$ (neutral $\mathrm{pH}$ ), extraction temperature of $70^{\circ} \mathrm{C}$ and the lowest extraction time at $70^{\circ} \mathrm{C}$, i.e. $20 \mathrm{~min}$. The result was in close support to the results reported by Fan et al., (2008) and Ruenroengklin et al., (2008).

The particle size and solid-liquid ratio (S/L) were varied. The particle sizes used were 300,600 and $1180 \mu \mathrm{m}$. The solid-liquid ratio was $1: 50,1: 100$ and $1: 150$. Here, the particle size refers to the size of the roselle powder, and $\mathrm{S} / \mathrm{L}$ refers to the ratio of powder to the solvent. The extraction processes were the same as that conducted in the first set of the experiment. The effect of particle size and solid-liquid ratio on the $\mathrm{pH}$ of the extract, the extraction of acid and the extraction of anthocyanins from the roselle powder were studied.

Effect on pH of the extract: The effect of particle size and solid-liquid ratio on the $\mathrm{pH}$ of the extract is shown graphically in Figure 1. The $\mathrm{pH}$ of the extract increased as the particle size was increased from 300 to $600 \mu \mathrm{m}$ but remained constant at $1180 \mu \mathrm{m}$, for solid-liquid ratio 1:50. At solid-liquid ratio of 1:100, $\mathrm{pH}$ increased first and then again decreased to the initial level with change of particle size from 300 to $1180 \mu \mathrm{m}$ through $600 \mu \mathrm{m}$, as shown in Figure 1. At S/L of 1:150, the $\mathrm{pH}$ of the extract remained fairly constant for 300 and $600 \mu \mathrm{m}$ while it decreased slightly for $1180 \mu \mathrm{m}$ particle size.

Statistical analysis revealed that the particle size and solidliquid ratio had no significant effects $(\mathrm{p}>0.05)$ on the $\mathrm{pH}$ of the extract. The interaction effect of particle size and solidliquid ratio was also insignificant $(\mathrm{p}>0.05)$. 


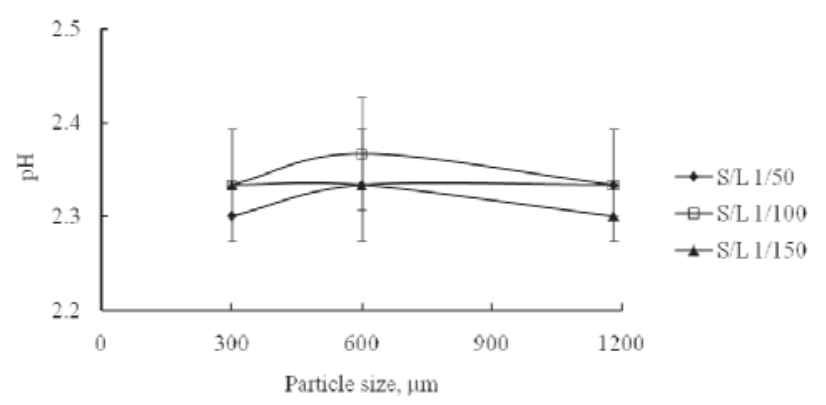

Figure 1. Effect of particle size and solid-liquid ratio on pH of the extract

Effect on extraction of acid: Figure 2, shows the effect of particle size and solid-liquid ratio on the extraction of acid. With the solid-liquid ratio of 1:50, a decreasing trend of the extraction of acid was observed for all particle sizes. The extraction of acid remained constant with particle sizes 300 and $600 \mu \mathrm{m}$, and increased slightly when the particle size was increased to $1180 \mu \mathrm{m}$, when solid-liquid ratio of 1:100 was used. When solid-liquid ratio was varied to $1: 150$, the extraction decreased initially with a rise later on as the particle sizes were varied as 300,600 and $1180 \mu \mathrm{m}$ respectively. Statistical analysis revealed that particle size and the interaction of particle size and solid-liquid ratio had no significant effect at $5 \%$ level of significance on the extraction of acid. But, solidliquid ratio had a significant effect $(\mathrm{p}<0.05)$.

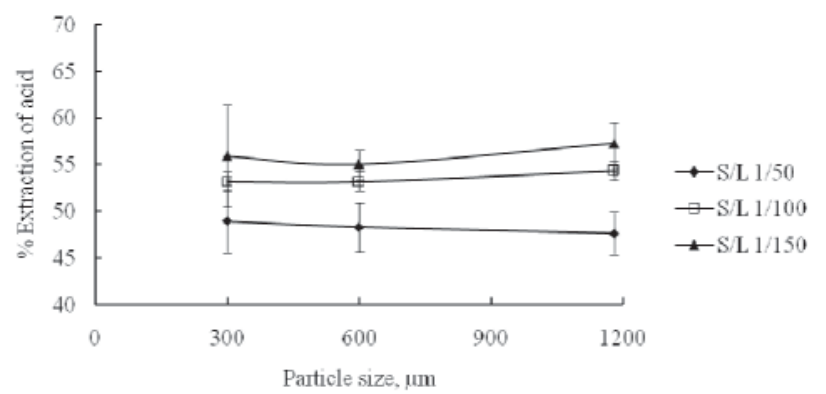

Figure 2. Effect of particle size and solid-liquid ratio on the extraction of acid

The extraction of acid from the roselle powder with 1:50 solidliquid ratio was significantly lower than those of 1:100 and 1:150 for all particle sizes. Extractions done at solid-liquid ratio of 1:100 and 1:150 were not different statistically in all the three cases. This could not be explained due to the unavailability or supporting literatures. The highest yield achieved with the ratio $1: 100$ was $54.34 \%$ and that with $1: 150$ was $57.24 \%$.

Effect on anthocyanins extraction: The effect of particle size and solid-liquid ratio on the extraction of anthocyanins is graphically presented in Figure 3. As seen from the graph, with solid-liquid ratio of 1:50, the extraction decreased with increase in particle size from 300 to $1180 \mu \mathrm{m}$. With solid-liquid ratio of 1:100, the extraction of anthocyanins increased as the particle size increased from 300 to $600 \mu \mathrm{m}$, but again decreased when the particle size was $1180 \mu \mathrm{m}$. A similar pattern was seen with the solid-liquid ratio of 1:150.

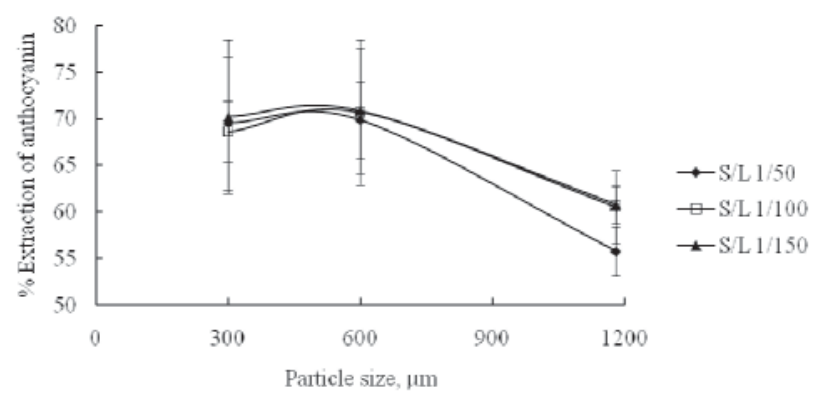

Figure 3. Effect of particle size and solid-liquid ratio on the extraction of anthocyanins

Statistical analysis revealed that the particle size of the roselle powder had a significant effect $(p<0.05)$ on the extraction of anthocyanins. However, the solid-liquid ratio and the interaction of particle-size and solid-liquid ratio had no significant effect at $5 \%$ level of significance $(p>0.05)$.

The extraction of anthocyanins in the extract with 300 and $600 \mu \mathrm{m}$ powders differed significantly with that of $1180 \mu \mathrm{m}$ powder, irrespective of the solid-liquid ratio; the former two being statistically the same and higher than the latter one. The extraction yield of $69.84 \%$ was obtained with the $\mathrm{S} / \mathrm{L}$ of $1: 50$ and $600 \mu \mathrm{m}$ powder.

It was seen from the result that the smaller the particle size, the more was the extraction of anthocyanins. The result agrees with the facts given by Gao and Mazza (1996) and Landbo and Meyer, (2001) reported that the reduction in particle size increases the yield of anthocyanins. No significant effect $(p>0.05)$ of solid-liquid ratio was seen. Gao and Mazza (1996) reported that the yield of anthocyanins was unaffected by the solid-liquid ratio. In contrary, Cacace and Mazza (2003) reported that the major factor affecting the extraction of anthocyanins was solvent-to-solid ratio.

Since the extraction of anthocyanins from 300 and $600 \mu \mathrm{m}$ powder were statistically the same, it could be better to choose the latter, as it would be more energy efficient process. Furthermore, the solid-liquid ratio of 1:50 would be appropriate to chose due to the use of less amount of solvent.

\section{Conclusion}

The total anthocyanins content in the calyces was found to be $310.48 \mathrm{mg} / 100 \mathrm{~g}(\mathrm{db})$. From the experimental result and consideration on the extraction of anthocyanins, the best extraction time, temperature and $\mathrm{pH}$ of the solvent were found to be $20 \mathrm{~min}, 70^{\circ} \mathrm{C}$ and 7.0 respectively. The particle size of powder significantly affected $(p<0.05)$ on the extraction of anthocyanins. The maximum anthocyanins extraction was obtained by using a solid-liquid ratio of 1:50 with solvent $\mathrm{pH}$ of 7.0 by using particle size of $600 \mu \mathrm{m}$ at $70^{\circ} \mathrm{C}$ for $20 \mathrm{~min}$. 


\section{Acknowledgements}

The author would like to acknowledge Dr. Benu P. Adhikari, The University of Ballarat, Australia and Mr. Atul Upadhyaya, The University of the Ryukyus, Japan for their kind support and suggestions during this work.

\section{References}

Alighourchi H. and Barzegar M. (2009). Some physicochemical characteristics and degradation kinetic of anthocyanin of reconstituted pomegranate juice during storage. $J$. FoodEng., 90: 179- 185.

Awika J. M., Rooney L.W. and Waniska R. D. (2004). Anthocyanins from black sorghum and their antioxidant properties. Food Chem., 90: 293-301.

Babalola S. O., Babalola A. O. and Aworh O. C. (2001). Compositional attributes of the calyces of roselle (Hibiscus sabdariffa L.). J. Food Technol. Africa, 6(4): 133-134.

Bridle P. and Timberlake C.F. (1997). Anthocyanins as natural food colors- selected aspects. Food Chem., 58(1-2): 103109.

Bronnum-Hansen K., Jacobsen F. and Flink J.M. (1985). Anthocyanin colorants from elderberry (Sambucus nigra L.). Process considerations for production of liquid extract. J. Food Technol., 20, 703-711. [Cited in Food Chem., 58(1-2):103-109(1997)].

Cacace J. E. and Mazza G. (2003). Optimization of extraction of anthocyanins from black currants with aqueous ethanol. J. Food Sci., 68(1): 240-248.

da Silva F. L., Escribano-Bailon M. T., Alonso J. J. P., RivasGonzalo J. C. and Santos-Buelga C. (2007). Anthocyanin pigments in strawberry. Lebensm. Wiss. U. Technol., 40: 374-382.

Dieci E. (1967). Sull'enocianina tecnica. Riv. Vitic. Enol., 12, 567-573. [Cited in Food Chem., 58(1-2): 103-109 (1997)].

Du C. T. and Francis F. J. (1973). Anthocyanins of roselle (Hibiscus sabdariffa). J. Food Sci., 38, 810-812. [Cited in Food Chem., 83: 423-436(2003)].

Fan G., Han Y., Gu Z. and Chen D. (2008). Optimizing conditions for anthocyanins extraction from purple sweet potato using response surface methodology (RSM). Lebensm. Wiss. u. Technol., 41: 155- 160.

Fan-Chiang H-J. and Wrolstad R. E. (2005). Anthocyanin pigment composition of blackberries. J. Food Sci., 70(3): C198-C202.

Gao L. and Mazza G. (1996). Extraction of anthocyanin pigments from purple sunflower hulls. J. Food Sci., 61(3): 600-603.

Idaka E. (1987, 1988). Acylated anthocyanins from red cabbage. Japanese patents. [Cited in Food Chem., 58(12): 103-109(1997)].
Landbo A. K. and Meyer A. S. (2001). Enzyme-assisted extraction of antioxidative phenols from blackcurrant juice press residues (Ribes nigrum). J. Agri. Food Chem., 49: 3169-3177.

Marti N., Perez-Vicente A. and Garcia-Viguera C. (2001). Influence of storage temperature and ascorbic acid addition on pomegranate juice. J. Sci. Food Agri., 82: 217-221.

Meyer A.S., Yi O-S., Pearson D.A., Waterhouse A.L. and Frankel E.N. (1997). Inhibition of human low density lipoprotein oxidation in relation to composition of phenolic antioxidants in grapes (Vitis vinifera). J. Agri. Food Chem., 45: 1638-1643.

Pazmino-Duran E. A., Giusti M. M., Wrolstad R. E. and Gloria M. B. A. (2001). Anthocyanins from Oxalis triangularis as potential food colorants. Food Chem., 75: 211-216.

Potter N. N. and Hotchkiss J. H. (1996). Food Science $\left(5^{\text {th }}\right.$ edn.). CBS Publishers and Distributors, New Delhi, pp 415.

Ranganna S. (2007). Handbook of Analysis and Quality Control for Fruit and Vegetable Products ( $2^{\text {nd }}$ edn.). Fifteenth Reprint. Tata McGraw-Hill Publishing Company Limited, New Delhi, pp1-30.

Ruenroengklin N., Zhong J, Duan X, Yang B., Li J. and Jiang Y. (2008). Effects of various temperatures and $\mathrm{pH}$ values on the extraction yield of phenolics from Litchi fruit pericarp tissue and the antioxidant activity of the extracted anthocyanins. Int. J. Mol. Sci., 9(7): 1333-1341.

Satue-Gracia M. T., Heinonen M. and Frankel E. N. (1997). Anthocyanins as antioxidants on human low-density lipoprotein and lecithin-liposome systems. J. Agric. Food Chem., 45: 3362-3367.

Shrivastava R. P. and Kumar S. (2002). Fruit and Vegetable Preservation- Principles and Practices ( $3^{\text {rd }}$ edn.). International Book Distributing Co., Lucknow, India, pp 361.

The Wealth of India (1997). Raw Materials. Volume V: H-K. National Institute of Science Communication. CSIR, New Delhi, pp 92-94.

Tsai P-J, McIntosh J., Pearce P., Camden B. and Jordan B. R. (2002). Anthocyanin and antioxidant capacity in Roselle (Hibiscus sabdariffa L.) extract. Food Res. Int., 35: 351356.

Wong D. W. S. (1996). Mechanism and Theory in Food Chemistry, $1^{\text {st }}$ Indian edition, CBS Publishers and Distributors, India, pp 160-165. 